\title{
CINÉTICA DE SECAGEM E PROPRIEDADES DE COZIMENTO DE MASSA DE ARROZ
}

Fernanda Suzana de Bona ${ }^{1}$, Ana Paula Biz ${ }^{2}$, Darlene Cavalheiro ${ }^{3}$, Cleiton $\mathrm{Vaz}^{3}$, Georgia Ane Raquel Sehn ${ }^{3}$

${ }^{1}$ Universidade do Estado de Santa Catarina, Departamento de Engenharia de Alimentos e Engenharia Química, graduada em Engenharia de Alimentos

2 Universidade Federal do Paraná, Departamento de Engenharia Química, mestranda em Engenharia de Alimentos

${ }^{3}$ Universidade do Estado de Santa Catarina, Departamento de Engenharia de Alimentos e Engenharia Química, professores do Departamento de Engenharia de Alimentos e Engenharia Química da UDESC Oeste

E-mail para contato: georgia.sehn@gmail.com

RESUMO - A produção de massas alimentícias gluten free é um desafio para a indústria de alimentos, pois busca-se substituir a rede de glúten formada pelas proteínas do trigo por outras fontes de cereais sem glúten, visando produtos finais com qualidade tecnológica. $\mathrm{O}$ objetivo deste estudo foi produzir massas alimentícias a base de arroz, secas em baixa (60 $\left.{ }^{\circ} \mathrm{C}\right)$ e alta temperatura $\left(100{ }^{\circ} \mathrm{C}\right)$, e avaliar a melhor formulação com base nas propriedades de cozimento e textura. Foram desenvolvidas cinco formulações de massas alimentícias com diferentes proporções de farinha e amido de arroz (F:A): 100:0, 75:25, 50:50, 25:75, $0: 100$. As curvas de secagem foram obtidas e diferentes modelos matemáticos, amplamente utilizados na secagem de cereais, foram ajustados aos dados. Em relação à cinética de secagem, os modelos matemáticos de Midilli e Page apresentaram a melhor correlação com os dados experimentais $\left(\mathrm{R}^{2}>0,94\right)$. Massas com maiores proporções de farinha de arroz apresentaram menores tempos de cozimento e maiores firmezas. As amostras secas a 100 ${ }^{\circ} \mathrm{C}$ apresentaram as menores perdas de sólidos na água de cozimento, sendo esse um parâmetro importante para definir a qualidade das massas alimentícias. A partir dos resultados obtidos observou-se que para fins de produção de massas glúten free base arroz, as formulações com proporções de farinha e amido de arroz 75:25 e 50:50 secas em alta temperatura $\left(100{ }^{\circ} \mathrm{C}\right)$ e com $100 \%$ de farinha de arroz seca a baixa temperatura $\left(60{ }^{\circ} \mathrm{C}\right)$ seriam as mais indicadas.

Palavras-chave: Farinha de arroz, Gluten free, Massa Alimentícia.

ABSTRACT - The production of gluten free pasta is a challenge for the food industry, as it seeks to replace the gluten network formed by wheat proteins with other sources of gluten-free cereals, aiming at end products with technological quality. The aim of this study was to produce rice-based pasta, dried at low $\left(60{ }^{\circ} \mathrm{C}\right)$ and high temperature $\left(100{ }^{\circ} \mathrm{C}\right)$, and to evaluate the best formulation based on cooking and texture properties. Five pasta formulations were developed with different proportions of rice flour and starch (F: A): 100: 
0, 75:25, 50:50, 25:75, 0: 100. The drying curves were obtained and different mathematical models, widely used in the drying of cereals, were adjusted to the data. Regarding drying kinetics, the mathematical models of Midilli and Page showed the best correlation with the experimental data $\left(\mathrm{R}^{2}>0.94\right)$. Pasta with higher proportions of rice flour showed shorter cooking times and greater firmness. The samples dried at $100^{\circ} \mathrm{C}$ showed the lowest loss of solids in the cooking water, which is an important parameter to define the quality of the pasta. From the results obtained it was observed that for the purpose of producing gluten free pasta based on rice, formulations with proportions of rice flour and starch 75:25 and $50: 50$ dried at high temperature $\left(100{ }^{\circ} \mathrm{C}\right)$ and with $100 \%$ of dry rice flour at low temperature $\left(60^{\circ} \mathrm{C}\right)$ would be the most suitable.

\section{INTRODUÇÃO}

A produção de alimentos sem glúten é um desafio para a indústria, pois busca-se substituir a rede de glúten formada pelas proteínas do trigo, por outras fontes de cereais sem glúten como o milho, o arroz, o amaranto, o trigo sarraceno, os amidos de fontes sem glúten e as farinhas de origem vegetal visando produtos finais com qualidade e consequente boa aceitação pelo consumidor (MARRIOTI et al., 2011).

A produção de massa sem glúten a base de farinha e/ou amido de arroz é uma prática muito comum, devido ao sabor suave, a cor branca, a alta digestibilidade e as propriedades hipoalergênicas do grão de arroz (PHONGTHAI et al., 2017). O amido de arroz apresenta boas propriedades estruturantes quando utilizado na elaboração de massas alimentícias, pois suas macromoléculas tendem a se reassociar e interagir após a gelatinização, resultando em estruturas que retardam a solubilização e o inchaço do amido durante o cozimento (LARROSA et al., 2016).

Industrialmente a tecnologia de secagem de massas alimentícias utiliza altas e baixas temperaturas. D'amico e colaboradores (2015) definiram que a secagem de massas em baixa temperatura é realizada entre $60{ }^{\circ} \mathrm{C}$ e $80{ }^{\circ} \mathrm{C}$, e a secagem em alta temperatura é realizada a $100{ }^{\circ} \mathrm{C}$. Pesquisas apontam que massas com glúten secas em altas temperaturas possuem melhor qualidade quando comparadas com as massas secas em baixas temperaturas, sendo que, após sua cocção, apresentam mínimas perdas de cozimento e maiores valores de firmeza (VILLENUEVE e GÉLINAS, 2007; CUBADDA et al., 2007).

Em processos de secagem, a modelagem matemática é fundamental para a otimização do processo de produção e para auxiliar no controle dos parâmetros operacionais (MURTHY et al., 2013). Os modelos matemáticos mais utilizados para estudar o comportamento da secagem são: Verna, Thompson, Page, Newton, Midilli, Logarítmico, Henderson e Pabis, Henderson e Pabis Modificado, Exponencial de Dois Termos, Dois Termos e Aproximação da difusão (DARVISHI et al., 2014; DOYMAZ et al., 2015; HORUZ et al., 2017).

Neste contexto, este trabalho tem como objetivo apresentar a cinética de secagem de massas produzidas com diferentes proporções de amido e farinha de arroz, secas em baixa e alta temperatura, e avaliar, com base nas propriedades de cozimento e textura qual a melhor proporção de farinha e amido para fabricação de massas gluten free a base de arroz.

\section{MATERIAIS E MÉTODOS}




\subsection{Material}

A farinha de arroz e o amido de arroz foram fornecidos pela empresa Palsgaard (Marechal Cândido Rondon, BRA) e a albumina de ovo líquida foi adquirida no comércio local de Pinhalzinho, SC, Brasil.

\subsection{Métodos}

Formulação e preparo das massas alimentícias: As massas foram produzidas no Departamento de Engenharia de Alimentos e Engenharia Química da UDESC (Pinhalzinho, SC, BRA) utilizando a seguinte formulação: $38 \mathrm{~g}$ de água; $12 \mathrm{~g}$ de albumina de ovo líquida; e $100 \mathrm{~g}$ da mistura de farinha de arroz e amido de arroz. Foram produzidas massas alimentícias com cinco diferentes proporções de farinha:amido: 0:100, 25:75, 50:50, 75:25 e 100:0.

Os ingredientes foram quantificados em balança semi-analítica (AD2000, Marte, BRA) e homogeneizados em uma batedeira (Turbo 360W Prime, Britânia, BRA) por cinco minutos, posteriormente, a massa foi mantida em repouso por quatro minutos. Em seguida, a massa foi extrusada em extrusora (HB800, Hidro, BRA) com uma trefila de espaguete de diâmetro de $4 \mathrm{~mm}$.

Secagem das massas alimentícias: O processo de secagem das massas foi realizado em estufa (CE-205, Cienlab, BRA). Inicialmente foi realizada uma pré-secagem das massas sem circulação de ar a $40{ }^{\circ} \mathrm{C}$ por 30 minutos e em seguida a secagem em baixa temperatura $\left(60{ }^{\circ} \mathrm{C}\right)$ ou em alta temperatura $\left(100{ }^{\circ} \mathrm{C}\right)$. Em ambas as temperaturas, a secagem foi conduzida durante 1 hora e 30 minutos com circulação forçada de ar. Após a secagem as massas foram embaladas em sacos plásticos de polietileno de alta densidade e armazenadas a temperatura ambiente até as análises.

Cinética de secagem das massas alimentícias: Para a obtenção das curvas de secagem foram realizadas análises de umidade, em duplicata, segundo o método 44-15.02 da AACCI (2010). As amostras foram coletadas durante o processo de secagem em intervalos de 5 minutos durante a primeira hora de secagem, e em intervalos de 10 minutos durante a segunda hora de secagem. A última determinação da massa foi realizada após 24 horas para cálculo da umidade de equilíbrio.

Os modelos matemáticos apresentados na Tabela 1 foram ajustados aos dados experimentais de secagem. Tais modelos são amplamente utilizados para descrever o fenômeno de secagem de cereais (MARTINAZZO et al., 2007; SILVA et al., 2017; SILVA et al., 2016; SMANIOTTO et al., 2017).

A razão de umidade experimental foi determinada pela Equação 1, conforme descrito por MARTINAZZO et al. (2007):

$$
R U=\frac{X-X_{e}}{X_{0}-X_{e}}
$$

Onde RU representa a razão da umidade (adimensional), X o teor de água no produto (base seca), $\mathrm{X}_{0}$ teor de água inicial do produto (base seca) e $\mathrm{X}_{\mathrm{e}} \mathrm{o}$ teor de água em equilíbrio no produto (base seca). 
Tabela 1 - Modelos matemáticos usados para descrever o processo de secagem das massas

\begin{tabular}{cc}
\hline Modelo & Equação \\
\hline Verna & $R U=a e^{-k t}+(1-a) e^{-k_{1} t}$ \\
Thompson & $R U=e^{\left\{\left[-a-\left(a^{2}+4 b t\right)^{0,5}\right] / 2 b\right\}}$ \\
Page & $R U=e^{-k t^{n}}$ \\
Newton & $R U=e^{-k t}$ \\
Midilli & $R U=a e^{-k t^{n}}+b t$ \\
Logarítmico & $R U=a e^{-k t}+c$ \\
Henderson e Pabis & $R U=a e^{-k t}$ \\
Henderson e Pabis Modificado & $R U=a e^{-k t}+b e^{-k_{0} t}+c e^{-k_{1} t}$ \\
Exponencial de Dois Termos & $R U=a e^{-k t}+(1-a) e^{-k a t}$ \\
Dois Termos & $R U=a e^{-k_{0} t}+b e^{-k_{1} t}$ \\
Aproximação da difusão & $R U=a e^{-k t}+(1-a) e^{-k b t}$ \\
\hline
\end{tabular}

RU: razão de umidade; a, b, c, n: constantes dos modelos; t: tempo de secagem (min.); k, $\mathrm{k}_{0}, \mathrm{k}_{1}$ : coeficientes de secagem $\left(\min ^{-1}\right)$.

Fonte: MARTINAZZO et al., 2007; SILVA et al., 2017; SILVA et al., 2016; SMANIOTTO et al., 2017.

Teste de cozimento das massas alimentícias: Os testes de cozimento foram realizados segundo o método 66-50.01 da AACCI (2010). Para avaliar o tempo de cozimento, a massa foi adicionada à água fervente e uma amostra foi removida em intervalos de 1 minuto. As amostras foram pressionadas entre duas placas de vidro e o tempo de cozimento ótimo foi definido como o tempo em que a linha central opaca (de amido não gelatinizado) desapareceu. A absorção de água da massa cozida foi determinada pela diferença da massa antes e depois da cozedura, usando o melhor tempo de cozimento, em triplicata. A perda de sólidos na água de cozimento foi determinada por evaporação de $25 \mathrm{~mL}$ da água de cozimento mais os resíduos lixiviados da massa em estufa a $105^{\circ} \mathrm{C}$ até massa constante, em triplicata.

Textura das massas alimentícias: A firmeza das massas alimentícias do estudo e da massa comercial foi avaliada conforme método 66-50.01 da AACCI (2010) utilizando um texturômetro (CT3, Brookfield, USA) com célula de carga de $50 \mathrm{~kg}$, onde cinco espaguetes foram dispostos horizontalmente sobre a placa inferior e comprimidos por um probe retangular de aço inoxidável $(70 \times 3 \mathrm{~mm})$. As especificações do ensaio foram: trigger $0,20 \mathrm{~N}$; velocidade $1,00 \mathrm{~m} / \mathrm{s}$; compressão de $1 \mathrm{~mm}$ de distância na amostra. A análise foi realizada em 6 repetições.

Análise estatística: A análise estatística foi realizada utilizando-se o software Statistica 12.0 (Statsoft, Tulsa, USA). Os resultados obtidos foram avaliados por cálculo de médias, desvio padrão, análise de variância e comparação múltipla de médias através do teste de Tukey $(\mathrm{p} \leq 0,05)$. A obtenção dos parâmetros a, b, c, n, k, ko, k (constantes dos modelos), R² (coeficiente de determinação) e SSR (erro quadrático) foi realizada utilizando regressão não-linear com a ferramenta Solver no programa Excel 2016.

\section{RESULTADOS E DISCUSSÕES}

\subsection{Cinética de secagem das massas alimentícias}


A Figura 1 apresenta as curvas de secagem das massas alimentícias glúten free nas duas temperaturas estudadas, $60{ }^{\circ} \mathrm{C}$ e $100^{\circ} \mathrm{C}$, para diferentes proporções de farinha e amido de arroz.

Figura 1 - Curvas de secagem das massas alimentícias produzidas com diferentes proporções de farinha (F) e amido (A) de arroz, secas a $60^{\circ} \mathrm{C}(\mathrm{A})$ e $100{ }^{\circ} \mathrm{C}(\mathrm{B})$
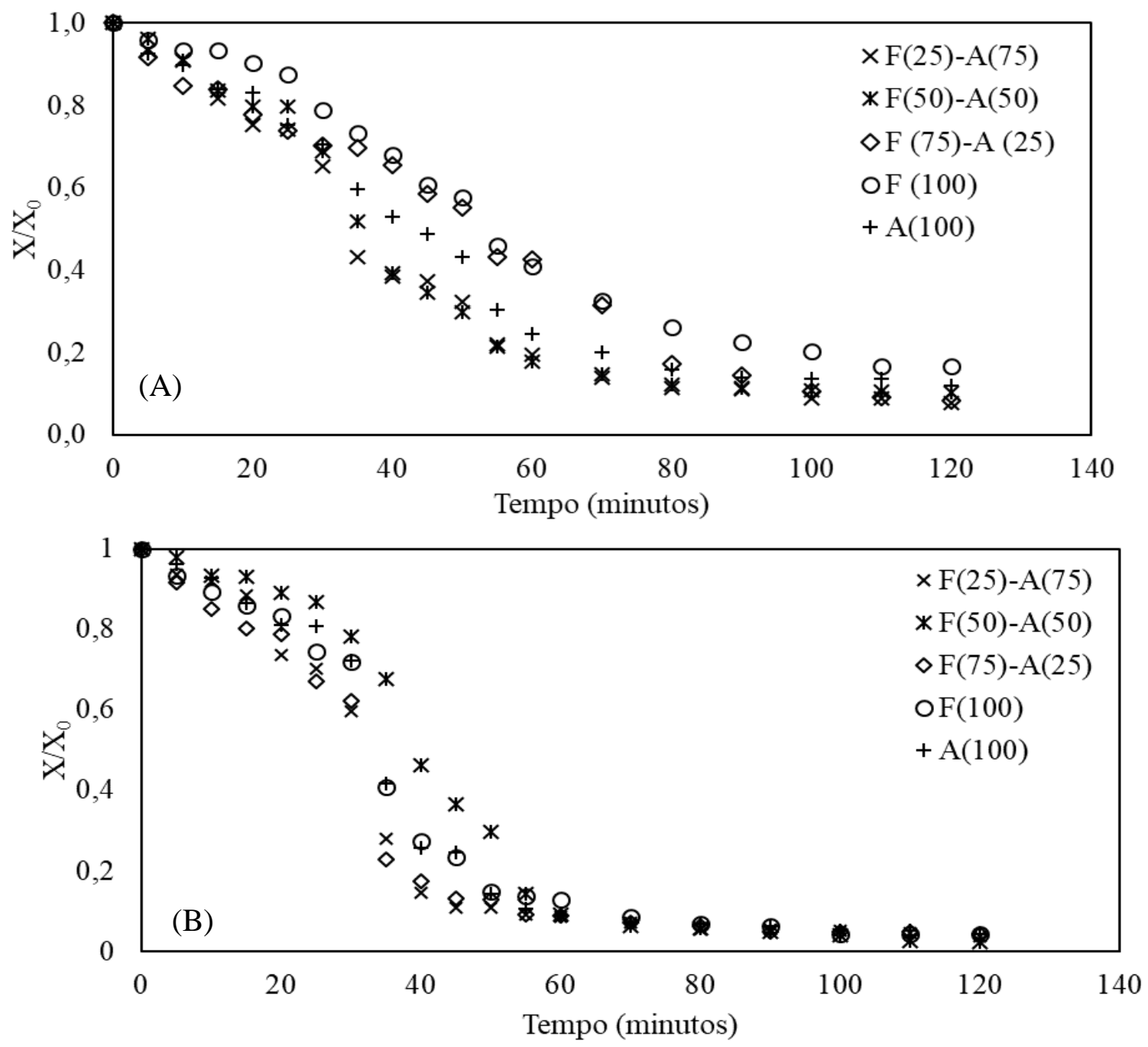

Fonte: elaborado pelo autor (2019)

Observa-se na Figura 1 que no período inicial da secagem houve uma perda de água acentuada, sendo que essa taxa foi diminuindo ao longo do tempo e em aproximadamente 80 minutos, as curvas de secagem tornaram-se constantes nos ensaios realizados em $100^{\circ} \mathrm{C}$. Para o processo realizado a $60{ }^{\circ} \mathrm{C}$, as curvas de secagem tornaram-se constante com aproximadamente 100 minutos. Essa diferença ocorre, 
pois, o uso de alta temperatura no processo de secagem proporciona maior taxa de transferência de massa (água), com isso atinge-se a umidade de equilíbrio mais rapidamente (MIRANDA et al., 2009).

Os modelos de Page e Midilli apresentaram uma ótima correlação com os dados obtidos experimentalmente, resultando em um coeficiente de determinação de $\mathrm{R}^{2}>0,94$, e os menores valores da soma dos erros ao quadrado (SSR) 0,0172 a 0,0676 e 0,0101 a 0,0295, respectivamente, para secagem a $60{ }^{\circ} \mathrm{C}$ e 0,0183 a 0,0822 e 0,0120 a 0,0414 respectivamente, para secagem a $100{ }^{\circ} \mathrm{C}$, ou seja, pode-se afirmar que esses modelos predizem de forma correta o comportamento das massas alimentícias gluten free, produzidas com diferentes proporções de farinha, durante o processo de secagem. Este resultado pode ser observado também na Figura 2 (a, b, c, d), onde há a comparação entre os dados experimentais e os dados obtidos usando os modelos da Page e Midilli.

Figura 2 - Relação entre as razões de umidade experimentais e as obtidas pelos modelos de Page em $60^{\circ}$ e $100{ }^{\circ} \mathrm{C}(\mathrm{a}, \mathrm{b})$ e Midilli em $60{ }^{\circ} \mathrm{C}$ e $100{ }^{\circ} \mathrm{C}(\mathrm{c}, \mathrm{d})$ com diferentes concentrações de farinha e amido de arroz
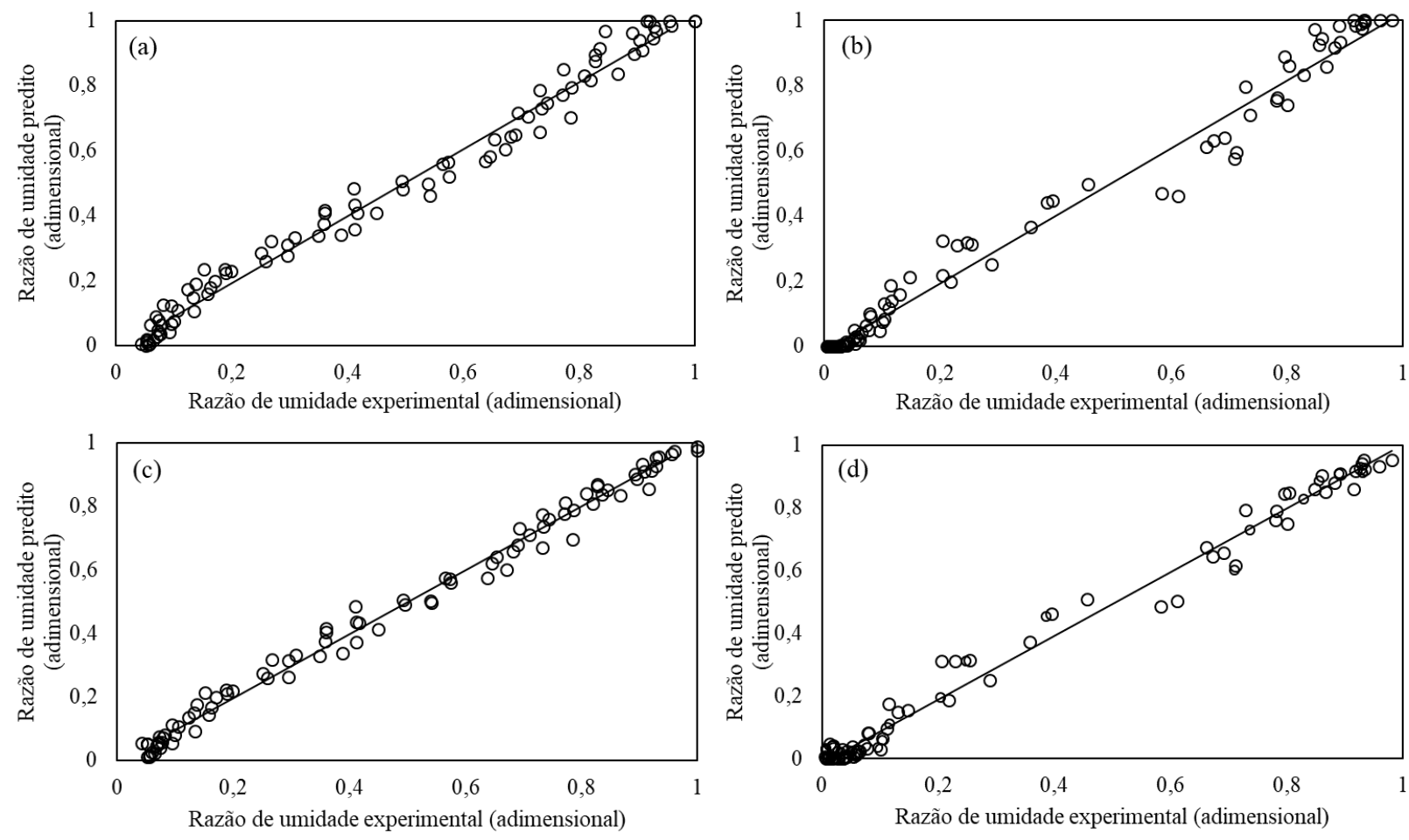

Fonte: elaborado pelo autor (2019)

Na Tabela 2 encontram-se os valores dos coeficientes " $k$ " e " $n$ " dos modelos matemáticos de Page e Midilli obtidos a partir de regressão não-linear. 
Tabela 2 - Parâmetros dos modelos matemáticos de Page e Midilli ajustados aos dados experimentais de secagem em $60{ }^{\circ} \mathrm{C}$ e $100{ }^{\circ} \mathrm{C}$.

\begin{tabular}{|c|c|c|c|c|}
\hline Modelo & Temperatura & Farinha:Amido $(\mathrm{g})$ & $\mathrm{k}\left(\min ^{-1}\right)$ & $\mathrm{n}$ \\
\hline \multirow{5}{*}{ Page } & \multirow{5}{*}{$60{ }^{\circ} \mathrm{C}$} & $25: 75$ & $3,9343 \times 10^{-}$ & 1,6103 \\
\hline & & $50: 50$ & $1,2151 \times 10^{-}$ & 1,9232 \\
\hline & & $75: 25$ & $5,5895 \times 10^{-}$ & 1,4291 \\
\hline & & $100: 0$ & $1,8710 \times 10^{-}$ & 1,6897 \\
\hline & & $0: 100$ & $5,5404 \times 10^{-}$ & 1,5177 \\
\hline \multirow{5}{*}{ Page } & \multirow{5}{*}{$100{ }^{\circ} \mathrm{C}$} & $25: 75$ & $6,3611 \times 10^{-}$ & 2,3589 \\
\hline & & $50: 50$ & $7,4172 \times 10^{-}$ & 2,7168 \\
\hline & & $75: 25$ & $1,7306 \times 10^{-}$ & 2,0548 \\
\hline & & 100:0 & $8,6477 \times 10^{-}$ & 2,1654 \\
\hline & & 0:100 & $3,5413 \times 10^{-}$ & 2,4224 \\
\hline \multirow{5}{*}{ Midilli } & \multirow{5}{*}{$60^{\circ} \mathrm{C}$} & $25: 75$ & $1,8501 \times 10^{-}$ & 1,8247 \\
\hline & & $50: 50$ & $1,1448 \times 10^{-}$ & 1,9384 \\
\hline & & $75: 25$ & $2,9316 \times 10^{-}$ & 2,1126 \\
\hline & & 100:0 & $8,8721 \times 10^{-}$ & 1,8683 \\
\hline & & 0:100 & $1,3198 \times 10^{-}$ & 1,8893 \\
\hline \multirow{5}{*}{ Midilli } & \multirow{5}{*}{$100{ }^{\circ} \mathrm{C}$} & $25: 75$ & $1,1737 \times 10^{-}$ & 2,8353 \\
\hline & & $50: 50$ & $2,1314 \times 10^{-}$ & 3,0374 \\
\hline & & $75: 25$ & $1,1551 \times 10^{-}$ & 3,5094 \\
\hline & & 100:0 & $8,3832 \times 10^{-}$ & 2,8122 \\
\hline & & $0: 100$ & $6,3866 \times 10^{-}$ & 2,8863 \\
\hline
\end{tabular}

Fonte: elaborado pelo autor (2019)

Pode-se observar através da Tabela 2 que os valores do parâmetro $\mathrm{n}$ aumentaram com o aumento da temperatura de secagem. Na literatura, o n reflete a resistência interna do produto ao processo de secagem (CORRÊA et al., 2007). Dantas e colaboradores (2015), encontraram um comportamento semelhante ao realizarem a cinética de secagem de massa alimentícia integral (adição de farelo de trigo em diferentes proporções), onde o parâmetro n obtido com o modelo de Midilli também aumentou com o aumento da temperatura do ar de secagem.

O parâmetro k nos modelos de Page e Midilli representa o efeito das condições externas de secagem (CORRÊA et al., 2007), nesse trabalho o valor de $\mathrm{k}$ diminuiu com o aumento da temperatura, como pode ser visto na Tabela 2 e isso também foi relatado em outros estudos de secagem de matrizes alimentícias (SANTOS et al., 2013; DANTAS et al., 2015). A literatura ainda aborda que a constante k pode ser utilizada de forma a caracterizar o efeito da temperatura no processo de secagem (CORREA et al., 2007).

\subsection{Propriedades de cozimento e textura das massas alimentícias}


Os resultados das análises de propriedades de cozimento e textura das massas alimentícias à base de arroz são apresentados na Tabela 3.

Tabela 3 - Propriedades de cozimento e textura das massas alimentícias a base de arroz secas em diferentes temperaturas e da massa comercial.

\begin{tabular}{cccccc}
\hline $\begin{array}{c}\text { Temperatura } \\
\text { de secagem }\end{array}$ & $\begin{array}{c}\text { Farinha:Amido } \\
(\mathrm{g})\end{array}$ & $\begin{array}{c}\text { Tempo de } \\
\text { Cozimento } \\
(\mathrm{min})\end{array}$ & $\begin{array}{c}\text { Absorção } \\
\text { de } \\
\text { Água }(\%)\end{array}$ & $\begin{array}{c}\text { Perda de } \\
\text { Sólidos }(\%)\end{array}$ & Firmeza (N) \\
\hline \multirow{2}{*}{$60^{\circ} \mathrm{C}$} & $100: 0$ & 7 & $123,29 \pm 3,46$ & $13,83 \pm 0,11^{\mathrm{c}}$ & $2,36 \pm 0,30^{\mathrm{a}}$ \\
& $75: 25$ & 8 & $159,95 \pm 6,08$ & $14,37 \pm 0,19^{\mathrm{l}}$ & $1,80 \pm 0,16^{\mathrm{b}}$ \\
& $50: 50$ & 9 & $169,87 \pm 1,29$ & $14,32 \pm 0,04^{\mathrm{l}}$ & $2,37 \pm 0,08^{\mathrm{a}}$ \\
& $25: 75$ & 11 & $197,11 \pm 1,93$ & $14,81 \pm 0,11^{\mathrm{c}}$ & $1,91 \pm 0,20^{\mathrm{b}}$ \\
& $0: 100$ & 14 & $183,58 \pm 1,39$ & $14,48 \pm 0,11^{\mathrm{l}}$ & $1,39 \pm 0,21^{\mathrm{c}}$ \\
\hline \multirow{2}{*}{$100^{\circ} \mathrm{C}$} & $100: 0$ & 8 & $184,09 \pm 2,23$ & $11,22 \pm 0,24^{\mathrm{l}}$ & $2,80 \pm 0,30^{\mathrm{a}}$ \\
& $75: 25$ & 9 & $163,42 \pm 1,05$ & $10,55 \pm 0,13^{\mathrm{c}}$ & $2,54 \pm 0,34^{\mathrm{ab}}$ \\
& $50: 50$ & 9 & $165,64 \pm 0,36$ & $10,41 \pm 0,10^{\mathrm{c}}$ & $2,26 \pm 0,19^{\mathrm{bc}}$ \\
& $25: 75$ & 12 & $192,71 \pm 1,82$ & $11,70 \pm 0,02^{\mathrm{c}}$ & $1,68 \pm 0,10^{\mathrm{d}}$ \\
& $0: 100$ & 14 & $182,75 \pm 2,50$ & $11,68 \pm 0,06^{\mathrm{c}}$ & $1,93 \pm 0,16^{\mathrm{cd}}$ \\
\hline
\end{tabular}

Média \pm desvio padrão. Letras diferentes na mesma coluna e na mesma temperatura de secagem, indicam diferença significativa $(\mathrm{p} \leq 0,05)$ pelo teste de Tukey.

Fonte: elaborado pelo autor (2019)

O tempo de cozimento das massas variou de 7 e 14 minutos, sendo que, quanto maior a proporção de amido na massa maior foi o tempo de cozimento. $\mathrm{O}$ aumento da fração de amido na mistura requer mais tempo para que ocorra a gelatinização na massa (PHONGTHAI et al., 2017). As temperaturas de gelatinização do amido de arroz e da farinha de arroz são diferentes, o amido de arroz apresenta temperatura de gelatinização mais elevada $\left(84,7{ }^{\circ} \mathrm{C}\right)$ quando comparada com a temperatura de gelatinização da farinha de arroz $\left(80,5^{\circ} \mathrm{C}\right)$, consequentemente, as massas contendo amido de arroz demoram mais tempo para cozinhar (COSTA, 2013).

Conforme os dados de porcentagem de absorção de água das massas apresentados na Tabela 3, foi possível verificar que as amostras com proporções de farinha e amido de 25:75 apresentaram maior absorção de água $\left(197,11 \%\right.$ e $192,71 \%$ para $60^{\circ} \mathrm{C}$ e $100^{\circ} \mathrm{C}$, respectivamente). Durante a gelatinização do amido de arroz os grãos de amido absorvem água e incham, com isso, quanto maior a quantidade de amido nas amostras mais elevada será a absorção de água, explicando o fato das amostras com mais amido em suas formulações absorveram mais água do que as amostras com maiores proporções de farinha de arroz. A amostra produzida apenas com farinha de arroz e seca a $60{ }^{\circ} \mathrm{C}$ foi a que menos absorveu água $(123,29 \%)$, sendo inclusive bem menor do que a mesma amostra, porém seca a $100{ }^{\circ} \mathrm{C}$ $(184,09 \%)$. Neste caso, observou-se que no processo de secagem em baixa temperatura o grau de gelatinização do amido é menor, resultando em uma menor absorção de água (YUE et al., 1999; GÜLER et al., 2002).

Em relação a perda de sólidos na água de cozimento observou-se que as massas secas a $100{ }^{\circ} \mathrm{C}$ apresentaram menor perda de sólidos na água de cozimento (variando de 10,41\% a 11,70 \%) quando 
comparadas com as massas secas a $60{ }^{\circ} \mathrm{C}$ (variando de $13,83 \%$ a $14,81 \%$ ). A quantidade de sólidos perdidos na água de cozimento depende do grau de gelatinização do amido, portanto, quanto mais elevada for a temperatura de secagem das massas maior será o grau de gelatinização do amido e, consequentemente, a perda de sólidos na água de cozimento será menor (ZHANG et al., 2013).

De maneira geral, as massas alimentícias com maiores quantidades de farinha de arroz, ou com proporções de 50:50 apresentaram maiores firmezas, exceto a amostra 75:25 seca a $60{ }^{\circ} \mathrm{C}$ (que apresentou $1,80 \mathrm{~N}$ ). Uma textura firme é desejável para evitar a ruptura durante a comercialização evitar a desintegração durante o cozimento e fornecer a textura conhecida como al dente no momento do consumo (FERNANDES et al., 2013).

\section{CONCLUSÃO}

Entre os modelos matemáticos aplicados, os de Midilli e Page foram os que melhores se ajustaram aos dados experimentais de secagem das massas a base de arroz, predizendo de forma eficiente o processo de secagem das massas em suas diferentes proporções de farinha e amido de arroz. A secagem em alta temperatura $\left(100^{\circ} \mathrm{C}\right)$ resultou em massas de melhor qualidade, ou seja, menor perda de sólidos no cozimento, sendo este um parâmetro importante para a indústria, pois indica que as massas apresentam boa tolerância ao cozimento e baixa solubilidade do amido. As massas secas em alta temperatura $\left(100{ }^{\circ} \mathrm{C}\right)$, nas proporções de 75:25 e 50:50 de farinha e amido de arroz, são as mais indicadas para fabricação de massas alimentícias gluten free a base de arroz. Já para as amostras secas a baixa temperatura $\left(60{ }^{\circ} \mathrm{C}\right)$, a amostra com $100 \%$ farinha de arroz é a mais indicada por apresentar baixa perda de sólidos e maior firmeza, mesmo sendo esta a que menos absorveu água no teste de cozimento.

\section{AGRADECIMENTOS}

Os autores agradecem à Universidade do Estado de Santa Catarina e à FAPESC (2019TR000648).

\section{REFERÊNCIAS}

AACCI - American Association of Cereal Chemists International. Approved methods. 11. ed. St. Paul, 2010.

CORRÊA, P. C. et al., Modelagem matemática para a descrição do processo de secagem do Feijão (Phaseoulus vulgaris L.) em camadas delgadas. Engenharia Agrícola, v. 27, n. 2, p. 501-510, maio/ago. 2007.

COSTA, M. C. Efeitos do armazenamento em parâmetros de avaliação de qualidade de grãos de quatro genótipos de arroz. 2013. Tese (Doutorado em Ciência e Tecnologia de Alimentos) - Programa de Pós-Graduação em Ciência e Tecnologia de Alimentos. Universidade Federal de Pelotas, Pelotas, 2013. 
CUBADDA, R. E. et al. Influence of gluten proteins and drying temperature on the cooking quality of durum wheat pasta. Cereal Chemistry, v. 84, n. 1, p. 48-55, jan/fev. 2007.

DANTAS, R. de L. et al. Cinética de secagem de massa alimentícia integral. Revista Brasileira de Produtos Agroindustriais, v. 17, n. 1, p. 11-15, 2015.

D'AMICO, S. et al. Effect of high temperature drying on gluten-free pasta properties. LWT - Food Science and Technology, v. 63, n. 1, p. 391-399, set. 2015.

DARVISHI, H. et al. Study of the drying kinetics of pepper. Journal of the Saudi Society of Agricultural Sciences, v. 13, n. 2, p. 130-138, jun. 2014.

DOYMAZ, I. et al. Microwave drying of green bean slices: drying kinetics and physical quality. Czech Journal of Food Sciences, v. 33, n. 4, p. 367-376, 2015.

GÜLER, S. et al. Effects of industrial pasta drying temperatures on starch properties and pasta quality. Food Research International, v. 35, n. 5, p. 421-427, 2002.

HORUZ, E. et al. Simultaneous application of microwave energy and hot air to whole drying process of apple slices: drying kinetics, modeling, temperature profile and energy aspect. Heat and Mass Transfer, v. 54, n. 2, p. 425-436, fev. 2018.

LARROSA, V. et al. Improvement of the texture and quality of cooked gluten-free pasta. LWT - Food Science and Technology, v. 70, p. 96-103, jun. 2016.

MARIOTTI, M. et al. The role of corn starch, amaranth flour, pea isolate, and Psyllium flouronthe rheological properties and the ultrastructure of gluten-free doughs. Food Research International, v. 42, p. 963-975, 2009.

MARTI, A. et al. Rice-based pasta: a comparison between conventional pasta-making and extrusioncooking. Journal of Cereal Science, v. 52, n. 3, p. 404-409, nov. 2010.

MARTINAZZO, A. P. et al. Análise e descrição matemática da cinética de secagem de folhas de capim limão. Revista Brasileira de Engenharia Agrícola e Ambiental, v. 11, n. 3, p. 301-306, 2007.

MIRANDA, M. et al. Influence of temperature on the drying kinetics, physicochemical properties, and antioxidant capacity of Aloe Vera (Aloe Barbadensils Miller) gel. Journal of Food Engineering, $\mathrm{v}$. 91, n. 2, p. 297-304, mar. 2009.

MURTHY, K. P. T.; MANOHAR, B. Hot air drying characteristics of mango ginger: Prediction of drying kinetics by mathematical modeling and artificial neural network. Journal of Food Science and Technology, v. 51, n. 12, p. 3712-3721, dez. 2013. 
FERNANDES, M. S. et al. Effect of adding unconventional raw materials on the technological properties of rice fresh pasta. Food Science and Technology, v. 33, n. 2, p. 257-264, 2013.

PHONGTHAI, S. et al. Effects of protein enrichment on the properties of rice flour based gluten-free pasta. LWT - Food Science and Technology, v. 80, p. 378-385, jul. 2017.

SILVA, B. R., et al. Estudo da cinética de secagem de polpa de carambola. Revista Brasileira de Tecnologia Agroindustrial, v. 10, n. 2, p. 2069-2080, 2016.

SILVA, C. D. et al. Estudo da modelagem de cinética de secagem da polpa de cupuaçu na produção de biopolímeros. Revista. Brasileira de Iniciação Científica, v. 4, n. 3, jul/set. 2017.

SMANIOTTO, S. A. T. et al. Drying kinetics of sunflower grains. Revista Brasileira de Engenharia Agrícola e Ambiental, v. 21, n. 3, p. 203-208, mar. 2017.

SANTOS, D. C. et al. Cinética de secagem de farinha de grãos residuais de urucum. Revista Brasileira de Engenharia Agrícola e Ambiental, v. 17, n. 2, p. 223-231, 2013.

VILLENUEVE, S.; GÉLINAS, P. Drying kinetics of whole durum wheat pasta according to temperature and relative humidity. LWT - Food Science and Technology, v. 40, n. 3, p. 465-471, abr. 2007.

YUE, P. et al. Effect of drying temperature on physicochemical properties of starch isolated from pasta. Cereal Chemistry, v. 76, p. 541-547, jul. 1999.

ZHANG, L. et al. Effects of different drying conditions on water absorption and gelatinization properties of pasta. Food and Bioprocess Technology, v. 6, n. 8, p. 2000-2009, ago. 2013. 